\title{
Relationships Among Ventral Striatal Dopamine Release, Cortisol Secretion, and Subjective Responses to Amphetamine
}

\author{
Lynn M Oswald', Dean F Wong' ${ }^{2}$, Mary McCaul', Yun Zhou' ${ }^{2}$, Hiroto Kuwabara ${ }^{2}$, Leena Choi ${ }^{3}$, James Brasic ${ }^{2}$ \\ and Gary S Wand*,4 \\ 'Department of Psychiatry and Behavioral Sciences, The Johns Hopkins University School of Medicine, Baltimore, MD, USA; ${ }^{2}$ Department of \\ Radiology and Radiological Science, The Johns Hopkins University School of Medicine, Baltimore, MD, USA; ${ }^{3}$ The Johns Hopkins University \\ Bloomberg School of Public Health, Baltimore, MD, USA; ${ }^{4}$ Department of Medicine, The Johns Hopkins University School of Medicine, Baltimore, \\ MD, USA
}

\begin{abstract}
There is evidence that stress and glucocorticoids alter drug self-administration and mesolimbic dopamine (DA) activity in preclinical models. The primary purpose of this study was to test the hypothesis that glucocorticoids are associated with psychostimulant reinforcement and DA release in humans. In total, 16 healthy adults, ages I8-27 years, underwent two consecutive 90-min PET studies with high specific activity [ ' $\mathrm{C}$ ]raclopride. The first scan was preceded by intravenous saline, and the second by intravenous amphetamine (AMPH $0.3 \mathrm{mg} / \mathrm{kg}$ ). DA release was defined as the percent change in raclopride binding between the placebo and AMPH scans. Measures of subjective drug effects, plasma cortisol, and growth hormone $(\mathrm{GH})$ were obtained. Findings showed that cortisol levels were positively associated with AMPH-induced DA release in the left ventral striatum (LVS) and the dorsal putamen. Subjects with higher cortisol responses to $\mathrm{AMPH}$ also reported more positive subjective drug effects than subjects with lower cortisol responses; no association was observed between cortisol levels and negative drug effects. Higher ratings of positive drug effects were also associated with greater DA release in the LVS, dorsal putamen, and dorsal caudate. A general lack of relationship was observed between GH responses to $\mathrm{AMPH}$ and $\mathrm{DA}$ release or subjective drug responses. Our findings provide evidence of interrelationships between glucocorticoid levels, subjective responses to $\mathrm{N}$ AMPH, and brain DA release in humans. The results are consistent with those of preclinical studies, suggesting that individual differences in HPA axis function may influence vulnerability to alcohol and drug dependence in humans.

Neuropsychopharmacology (2005) 30, 82 I-832, advance online publication, 9 February 2005; doi: I 0. I 038/sj.npp. I 300667
\end{abstract}

Keywords: cortisol; dopamine; positron emission tomography (PET); reinforcement; human; amphetamine

\section{INTRODUCTION}

In recent years, there has been increasing interest in neurobiological mechanisms that underlie ethanol and drug reinforcement. Considerable evidence has emerged from preclinical studies suggesting that drugs of abuse act through mechanisms involving mesocorticolimbic dopamine (DA) pathways. A region at the base of the striatum, the nucleus accumbens $\left(\mathrm{NA}_{\mathrm{cc}}\right)$ appears to be the key zone involved in the rewarding effects of drugs. Findings from preclinical studies have shown that psychostimulants, opioids, and alcohol all increase synaptic DA accumulation

* Correspondence: Professor GS Wand, Department of Medicine and Psychiatry, Ross Research Building, Room 863, 720 Rutland Avenue, Baltimore, MD 21205, USA, Tel: + I 410955 7225, Fax: + I 410955 084 I, E-mail: gwand@jhmi.edu

Received I September 2004; revised I 8 November 2004; accepted I December 2004

Online publication: 7 December 2004 at http://www.acnp.org/citations/ Npp I 2070404040 I/default.pdf within this important brain region (Bonci et al, 2003; Doyon et al, 2003; Koob, 1992, 2003; Spanagel and Weiss, 1999; Wise, 1998). Drug reward can be reduced or attenuated by pharmacological or genetic manipulations that alter mesolimbic DA neurotransmission (Liu and Weiss, 2002; Phillips et al, 1998; Samson and Hodge, 1993).

Findings from numerous clinical studies have confirmed popular beliefs that stress contributes to the development, maintenance, and outcome of substance abuse disorders in humans (Brewer et al, 1998; Brown et al, 1990; Cole et al, 1990; Karlsgodt et al, 2003; King et al, 2003; Sussman and Dent, 2000). Findings from human laboratory studies have further shown that stress increases drug craving (Sinha et al, $1999,2000,2003)$ alters subjective responses to alcohol (Soderpalm and de Wit, 2002) and increases alcohol consumption (de Wit et al, 2003; Hull and Young, 1983). There is also evidence that genetic influences on stress reactivity may be associated with individual differences in risk for alcoholism (Bau et al, 2000; Dai et al, 2002a, b; King et al, 2002; Madrid et al, 2001; Ohannessian et al, 1994; 
Schuckit et al, 1996; Waltman et al, 1994; Wand et al, 2001, $1998,1999 \mathrm{a}, \mathrm{b})$ and that the dynamics of the physiological stress response may be deranged in drug dependent individuals (Errico et al, 2002; Kemper et al, 1990; Kreek and Koob, 1998).

There is growing evidence that glucocorticoids are important mediators of the relationship between stress and drug-seeking behavior rodents (Marinelli and Piazza, 2002; Piazza and Le Moal, 1998). Several types of stressful experiences enhance rates of responding for drugs of abuse and facilitate the acquisition and reinstatement of psychostimulant, alcohol, and opiate self-administration in animals (Erb et al, 1996; Le et al, 1998; Piazza and Le Moal, 1997, 1998; Shaham et al, 2000; Tidey and Miczek, 1996). High levels of glucocorticoids have also been shown to increase rates of responding for psychostimulant drugs (Goeders and Guerin, 1996b; Piazza et al, 1991). Acquisition and reinstatement of cocaine-seeking behavior is reduced by glucocorticoid suppression with ketoconazole (Campbell and Carroll, 2001; Goeders and Clampitt, 2002), and alcohol consumption has been shown to be reduced by acute administration of the glucocorticoid receptor antagonist mifepristone (Koenig and Olive, 2004). Furthermore, adrenalectomy has been shown to attenuate psychostimulant self-administration (Deroche et al, 1997; Goeders and Guerin, 1996a) and to reduce the amount of alcohol intake in alcohol-preferring rats (Fahlke et al, 1994); these effects can be reversed by exogenous corticosterone replacement.

Although the behavioral and neuronal mechanisms underlying the relationship between stress and drug selfadministration are not well understood, it is hypothesized that stress interacts with the rewarding properties of drugs of abuse by altering mesocorticolimbic DA neurotransmission (Marinelli and Piazza, 2002). Preclinical findings have shown that stress and glucocorticoids not only increase levels of mesolimbic DA but also interact with the effects of drugs of abuse on this neurotransmitter system (Barrot et al, 2001; Cho and Little, 1999; Marinelli and Piazza, 2002; Yavich and Tiihonen, 2000). Nevertheless, findings from human laboratory studies have not been consistent with those of the preclinical literature in demonstrating relationships between glucocorticoids and psychostimulant reinforcement (Alessi et al, 2003; Harris et al, 2003; Wachtel et al, 2001). Since it has been more difficult to study the neurochemical mechanisms that underlie behavioral effects of drugs in humans, the role of glucocorticoids in drug reinforcement and the relevance of the relationship between glucocorticoids and DA neurotransmission in humans remain ambiguous.

Fortunately, within the past decade it has become possible to examine the effects of drugs of abuse on DA neurotransmission in living human beings with the use of noninvasive PET scan technology. Importantly, since humans can describe their mood and feelings, this technology has made it possible to measure drug-induced alterations in brain DA activity as subjects verbally provide information about their immediate subjective experiences to the drug. Volkow et al (1994) were the first to demonstrate that stimulants induce brain DA release in humans. Findings of several subsequent studies showed that stimulant-induced DA release and $D_{2}$ receptor availability are positively associated with euphoric drug responses in healthy volunteers (Drevets et al, 2001; Laruelle et al, 1995; Leyton et al, 2002; Martinez et al, 2003; Schlaepfer et al, 1997; Volkow et al, 1999, 2002b).

In the present study, we utilized PET methodology to conduct the first examination of relationships among AMPH-induced DA release, cortisol secretion, and subjective drug responses in healthy, young adults. Findings from several prior investigations have shown that plasma levels of glucocorticoids and ACTH are increased by acute administration of AMPH in both rodents and humans (Halbreich et al, 1981; Jacobs et al, 1989; Smith et al, 2004; Swerdlow et al, 1993). Based on the observations cited above, we hypothesized that cortisol responses to AMPH would be positively correlated with drug-induced DA release, as well as with the positive subjective effects of AMPH. To evaluate whether any such effects were specific to cortisol, we conducted similar analyses for another 'stress' hormone, that is, growth hormone (GH).

\section{MATERIALS AND METHODS}

\section{Subjects}

In total, 16 healthy male and female subjects between the ages of 18 and 27 years were recruited by newspaper advertisements and posted fliers. After complete description of the study, all volunteers provided written informed consent, approved by the Johns Hopkins Medicine Institutional Review Board. Screening included a medical history and physical examination, blood chemistry profile, complete blood count, electrocardiogram, urinalysis, alcohol breathalyzer test, and urine toxicology screen. The SemiStructured Assessment for the Genetics of Alcoholism (SSAGA) (Bucholz et al, 1994) was administered by a Master's level interviewer to screen for DSM-IV axis I psychiatric diagnoses. Exclusion criteria included: (a) serious medical conditions, (b) presence of a DSM-IV axis I disorder, including alcohol/drug dependence or abuse, (c) use of any psychoactive medications within the past 30 days, (d) treatment in the last 6 months with antidepressants, neuroleptics, sedative hypnotics, glucocorticoids, appetite suppressants, opiate, or DA medications, (e) seizure disorder or history of closed head trauma, (f) report drinking more than 30 drinks per month, (g) unable to provide clean urine drug screens at intake or during study participation, and (h) pregnancy or lack of effective nonhormonal methods of birth control in females. Demographic characteristics of the sample are shown in Table 1. All subjects were nonsmokers who reported light to moderate use of alcohol and no use of illicit drugs or psychoactive medications for at least 30 days prior to participation.

\section{MRI Assessment and Mask Fitting}

Each subject was fitted for a thermoplastic mask modeled to his/her face prior to GCRC admission. The MRIs were acquired to (1) optimize the available field of view of the PET camera; (2) customize positioning of the patient so the largest transaxial extension of the basal ganglia is in a direct slice; and (3) make possible data acquisition from the cerebellum, frontal and parietal cortices at the same time. 
Table I Subject Characteristics ${ }^{\mathrm{a}}$

\begin{tabular}{lc} 
Race/ethnicity (n) & \\
White, not Hispanic origin & I। \\
Black, not Hispanic origin & 3 \\
Asian & 1 \\
White, Hispanic origin & 1 \\
& \\
Gender (n) & 9 \\
Male & 7 \\
Female & \\
Age (years) & $21.1(2.6)$ \\
BMl & $24.3(2.7)$ \\
Education (years) & $14.3(1.7)$ \\
Drinks/week (range 0.I-8.8) & $2.1(2.6)$ \\
\hline
\end{tabular}

${ }^{a}$ Values represent means and standard deviations or absolute numbers.

Use of the MRI allowed co-registration of the emission images so that anatomically accurate regions of interest (ROIs) could be drawn on the MRI. The MRIs were acquired with at least two sequences: an SPGR (spoiled grass sequence) with $1.5-\mathrm{mm}$ thick slices, and a double echo (proton density and $\mathrm{T} 2$ weighted, 5-mm thick slices). The former one was used more frequently for co-registration and segmentation, the latter served as a diagnostic scan and to segment extracerebral CSF. The MRIs were rotated and resampled to match the position and resolution of the PET slices, so ROIs could be transferred easily from one modality to the other.

\section{PET Procedures and Data Acquisition}

Subjects were admitted to the Johns Hopkins Hospital General Clinical Research Center (GCRC) in-patient unit the day before the PET procedures. They were instructed not to ingest any alcohol, drugs, or over the counter medications for $48 \mathrm{~h}$ prior to admission. Laboratory studies upon admission included a urine toxicology screen, alcohol breathalyzer test, hematocryte, electrolyte panel, and urine pregnancy screen for females. Subjects received a calorie controlled, caffeine-free breakfast prior to the PET procedures. Beginning at 0830, subjects underwent two, consecutive 90 -min PET scans with $\left[{ }^{11} \mathrm{C}\right]$ raclopride (RAC). This radioligand is a low-affinity antagonist at D2 and D3 receptors that has previously been shown to be sensitive to stimulant-induced changes in DA concentration in the brain (Endres et al, 1997; Volkow et al, 1994). A high specific activity intravenous bolus injection of approximately $18 \mathrm{mCi}\left[{ }^{11} \mathrm{C}\right] \mathrm{RAC}$ was administered at the beginning of each scan. The first scan was preceded at -5 min by an intravenous injection of saline; the second scan was preceded at $-5 \mathrm{~min}$ by $0.3 \mathrm{mg} / \mathrm{kg} \mathrm{AMPH}$, each delivered over $3 \mathrm{~min}$. The scanning image protocol consisted of up to 32 scan acquisitions, starting from a 15-s duration and increasing to $6 \mathrm{~min}$ in length over a $90-\mathrm{min}$ period in 3-D mode. All images were acquired on the 3D GE Advance whole body PET scanner and were preceded by a 10 -min attenuation scan employing a rotating germanium-68 source. Subjects were under continuous cardiovascular monitoring during the scans. They were permitted to get up briefly after the first scan and were repositioned on the scanner table for the second. Following the scans, subjects were escorted back to the GCRC where they were evaluated by a physician prior to discharge.

\section{Subjective Measures}

Analog rating scales were administered $15 \mathrm{~min}$ before each scan and 3,6,10,15,25, 55, and 85 min after placebo and AMPH administration. Subjects were asked to verbally rate the degree to which they were experiencing each of 10 possible drug effects. Positive stimulant effects included 'high', 'rush', 'good effects', 'liking', 'desire for drug'; negative effects included 'fidgety', 'anxious', 'dizziness', 'dry mouth', and 'distrust' (Bigelow and Walsh, 1998). Each effect was rated on a 5-point scale ranging from 'least' to 'most'.

\section{Hormone Assays}

Measurements of plasma cortisol and GH were obtained at baseline $(-25$ and $-5 \mathrm{~min})$ and at scheduled intervals $(+15,+35,+55$, and $+75 \mathrm{~min})$ during the scans. Plasma cortisol concentrations were measured by Radioimmunoassay (Diagnostic Products Corporation, Inc., Los Angeles, CA). Intra- and interassay coefficients of variation were 5.2 and $8.0 \%$, respectively. Plasma concentrations of GH were assayed by a two-site IRMA (Nichols immunoradiometric assay). The intra-assay coefficient of variation was $9.9 \%$.

\section{ROI Definition}

Preclinical findings indicate that the $\mathrm{NA}_{\mathrm{cc}}$, a region at the base of the striatum, is the primary target for the reinforcing effects of drugs of abuse (Howell and Wilcox, 2002; Spanagel and Weiss, 1999). Nevertheless, aggregate findings from PET studies suggest that more information is needed about the relative importance and involvement of the dorsal caudate and putamen in humans (Drevets et al, 2001; Leyton et al, 2002; Martinez et al, 2003). Therefore, the ROIs for the present study included the left (LVS) and right (RVS) ventral striatum, the left (LDP) and right (RDP) dorsal putamen, and the left $(\mathrm{LDCH})$ and right $(\mathrm{RDCH})$ dorsal caudate nucleus.

To obtain regional BP values, volumes of interests (VOIs) were defined on spoiled gradient (SPGR) magnetic resonance imaging (MRI) volumes for the caudate nucleus and the putamen bilaterally, using interactive segmentation software. The program selects upper and lower MRI intensity thresholds to delineate striatal structures from surrounding structures with minimal hand drawing. The ventral striatum (VS) is automatically defined on the SPGR MRI volume reoriented so the plane containing the midline separating the left and right halves of the brain is orthogonal to the horizontal ACPC plane, which is the plane containing the points representing the anterior commissure and the posterior commissure. On each coronal slice, the VS was defined as the portion of the striatal VOIs ventral to the line crossing the ventral corner of the lateral 
ventricle and perpendicular to the bisector of the internal capsule (Baumann et al, 1999). The MRI volume was spatially aligned to the PET volumes (averaged volumes across frames taken between 30 and $90 \mathrm{~min}$ after tracerinjection) using information theory advanced by Collignon et al (1995) and implemented in SPM2b software (Friston, 2002). The same transformation parameters were applied to transfer VOIs from MRI space to PET space.

\section{Modeling of PET Outcome Measures}

$\left[{ }^{11} \mathrm{C}\right] \mathrm{RAC}$ D2-like receptor specific binding was measured with binding potential (BP) $=B_{\max } / \mathrm{Kd}$ (Wong, 2002). A simplified reference tissue models (SRTM) was used to describe voxel tracer kinetics, and cerebellum was used as a reference tissue (Lammertsma and Hume, 1996). Since the cerebellum in nearly devoid of D2 and D3 receptors, specific binding of $\left[{ }^{11} \mathrm{C}\right] \mathrm{RAC}$ is thought to be negligible in the cerebellum. Based on the SRTM model, a linear regression with spatial constraint algorithm was used to generate parametric BP images (Zhou et al, 2003). The VOIs defined on MRI images were transferred to BP images to obtain VOI $\mathrm{BP}$ values. The VOI DA release was estimated as the percent change in $\mathrm{BP}$ from the placebo to the $\mathrm{AMPH}$ scans: $\left(\left(\mathrm{BP}_{\mathrm{PL}}-\mathrm{BP}_{\mathrm{AMPH}}\right) / \mathrm{BP}_{\mathrm{PL}}\right) \times 100$; lower $\mathrm{BP}$ values during the AMPH scan indicate greater levels of endogenous DA. It should be noted that our use of the term 'DA release' does not convey a full description of the mechanisms by which AMPH alters DA concentration. Although the term 'DA release' has been used conventionally in the PET literature to describe AMPH-induced changes in $\left[{ }^{11} \mathrm{C}\right] \mathrm{RAC} \mathrm{BP}$, the increases in DA concentrations that occur following AMPH administration probably result from several different mechanisms of action. These mechanisms may include DA reuptake blockade, reverse transport of DA through the DA transporter (Schmitz et al, 2001), as well as possible actions on endogenous opioid systems (Schad et al, 2002).

\section{Statistical Analyses}

Our primary hypotheses were that (1) cortisol responses to AMPH would be positively associated with AMPH-induced DA release, (2) cortisol responses to AMPH would be positively associated with self-report ratings of positive subjective drug effects, and (3) positive subjective drug effects would be positively associated with ventral striatal DA release. Primary outcome measures included DA release, visual analog ratings of subjective drug responses, and plasma cortisol levels. DA release was defined as described above. Visual analog ratings were summarized as area under the curve time response curve (AUC), calculated by trapezoidal approximation from 3 to $85 \mathrm{~min}$ following drug administration. Several of the analog scores were square root transformed due to non-normality. Cortisol outcomes were evaluated as both the original plasma cortisol levels measured over time and an AUC summary measure. The AUC measure was calculated by trapezoidal approximation from $5 \mathrm{~min}$ before to $75 \mathrm{~min}$ after drug administration; baseline AUC $(-25$ to $-5 \mathrm{~min})$ was subtracted from this value. To evaluate the specificity of findings related to cortisol, GH levels were obtained at the same times as cortisol levels; summary scores were calculated identically. GH data were log transformed due to non-normality.

Longitudinal analyses with drug session (ie placebo or $\mathrm{AMPH}$ ) and drug condition (ie pre- and postdrug) as indicator variables were used for preliminary examination of differences in plasma hormone levels across sessions. Relationships between placebo and AMPH session cortisol levels were further evaluated with Pearson correlation coefficients. Differences in BP values and in analog ratings across sessions were evaluated with paired $t$-tests or Wilcoxon signed ranks tests as indicated. The sample consisted of 16 subjects; however, two subjects completed the study before the analog and state anxiety scales were included in the protocol. Therefore, analyses involving these measures were conducted with 14 subjects.

Each of the primary hypotheses was examined with longitudinal analyses, taking into account within subject correlations among repeated measurements from individual subjects. Since our sample size was relatively small, we attempted to keep the number of covariates in the models to a minimum. Gender and drinking history (ie drinks/week) were included to adjust for the effects of demographic differences. Level of education and BMI were not controlled due to their restricted ranges; race was not included due to the limited number of nonwhite subjects. Although there is prior evidence that DA neurotransmission declines with age (Backman et al, 2000; van Dyck et al, 2002; Volkow et al, 2002a), findings from simple correlations showed that age was not associated with DA release, cortisol levels, or subjective drug responses in the present sample. We suspect that the lack of relationship was due to the restricted age range of the sample (all but three of the subjects were between 19 and 24 years old); age was not included as a covariate in the final models.

To examine the first hypothesis, plasma cortisol levels measured over time were used as the outcome variable. The models included indicator variables for drug session (ie placebo or AMPH) and drug condition (ie pre- and postdrug), DA release in a specific region of the striatum, interaction terms between the indicator variables and DA release as major covariates of interest, time and time ${ }^{2}$ for both placebo and active session to adjust nonlinear time trend, and demographic covariates (ie gender and drinking history). Separate models were run for each of the striatal regions. To examine the second hypothesis, AUC scores for each of the analog scales were used as outcome variables. The models included an indicator variable for drug session (ie placebo or AMPH), cortisol AUC scores as a timevarying covariate, an interaction term between the indicator variable and the cortisol AUC scores as major covariates of interest, and demographic covariates. To examine the third hypothesis, AUC scores for each of the analog scales were used as outcome variables. The models included an indicator variable for drug session (ie placebo or AMPH), DA release in a given region, an interaction term between the indicator variable and DA release as major covariates of interest, and demographic covariates. Secondary analyses involving $\mathrm{GH}$ were conducted as described for those involving cortisol.

Bonferroni corrections were used to adjust for multiple comparisons. Significance levels for the first two hypotheses were based on the number of comparisons in each set of 
analyses, that is, the level for the first hypothesis was set at 0.008 (0.05 divided by 6) and the level for the second hypothesis was set at 0.005 ( 0.05 divided by 10$)$. Examination of the third hypothesis involved 10 analog scales and six brain regions, which would require a significance level of 0.0008 (0.05 divided by 60) with Bonferroni adjustment. However, the Bonferroni assumes that variables are independent (Wang et al, 2000); whereas both the regional DA release values and the scores on several of the analog scales were found to be highly intercorrelated. As we felt that the Bonferroni correction would seriously inflate the probability of Type II errors in the last set of analyses, we set a conservative, but less stringent criteria of 0.005 , which was based on the number of analog scales used in the comparisons. Findings from preliminary analyses are reported as uncorrected $p$-values ( 0.05 level of significance). All analyses were conducted with SAS 8.1 or STATA 8.0.

\section{RESULTS}

\section{Cortisol and DA Release}

Figure 1 displays mean levels of cortisol and GH over time during the placebo and AMPH sessions. Cortisol levels prior to placebo (ie predrug baseline) did not differ from cortisol levels prior to AMPH. A significant increase in cortisol over baseline levels was observed for responses to AMPH $(z=4.75, p<0.0001)$ but not for responses to placebo;
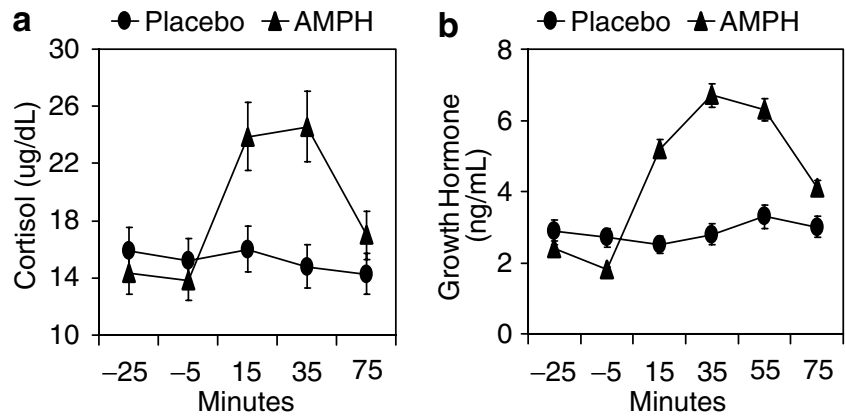

Figure I Plasma cortisol (a) and growth hormone (b) levels during the placebo and amphetamine PET scans. Means and standard errors are shown at each time point during each of the scans.
AMPH-induced cortisol responses were also significantly greater than cortisol responses during the placebo session $(z=6.22, p<0.0001)$. Although responses to AMPH were greater in magnitude than responses to placebo, significant correlations were found in cortisol levels between sessions; individuals with greater cortisol reactivity during the AMPH session also had greater reactivity during the placebo session (data not shown). Effects of AMPH on $\left[{ }^{11} \mathrm{C}\right] \mathrm{RAC}$ $\mathrm{BP}$ are shown in Table 2. Significant decreases were noted in $\left[{ }^{11} \mathrm{C}\right] \mathrm{RAC}$ binding (ie increased DA release) in all of the striatal subregions with AMPH; DA release values across most of the subregions were highly intercorrelated (data not shown). Findings from the longitudinal analyses indicated that cortisol responses to AMPH were positively associated with DA release in the LVS and the left dorsal putamen (see Table 3). Positive associations were also observed between unstimulated cortisol levels and DA release in the putamen. The relationship between LVS DA release and cortisol AUC during the AMPH session is shown in Figure 2.

To evaluate the specificity of the relationship between cortisol and DA release, GH measurements were also analyzed. Baseline levels of GH were marginally higher during the placebo session than during the AMPH session $(z=1.89, p=0.059)$. Levels of GH increased marginally from baseline following placebo administration $(z=1.94$, $p=0.052)$ and increased significantly following AMPH $(z=3.02, p=0.002)$. GH responses to AMPH were significantly higher than $\mathrm{GH}$ responses to placebo $(z=2.65$,

Table 2 Raclopride Binding Potentials during Placebo and Amphetamine PET Scans ${ }^{\mathrm{a}}$

\begin{tabular}{lcccc}
\hline Region & Placebo & Amphetamine & Difference (\%) & p-values \\
\hline LVS & $2.89 \pm 0.34$ & $2.58 \pm 0.33$ & $-10.66 \pm 5.13$ & $<0.0001$ \\
RVS & $2.84 \pm 0.45$ & $2.56 \pm 0.34$ & $-9.26 \pm 5.59$ & $<0.0001$ \\
LDP & $3.19 \pm 0.25$ & $2.64 \pm 0.21$ & $-16.90 \pm 4.67$ & $<0.0001$ \\
RDP & $3.26 \pm 0.32$ & $2.69 \pm 0.22$ & $-17.14 \pm 5.43$ & $<0.0001$ \\
LDCH & $2.49 \pm 0.27$ & $2.35 \pm 0.21$ & $-5.25 \pm 4.89$ & $<0.002$ \\
RDCH & $2.51 \pm 0.28$ & $2.40 \pm 0.24$ & $-4.27 \pm 3.07$ & $<0.0001$ \\
\hline
\end{tabular}

${ }^{a}$ Values represent mean $\pm S D$. LVS $=$ left ventral striatum, RVS = right ventral striatum, $\mathrm{LDP}=$ left dorsal putamen, $\mathrm{RDP}=$ right dorsal putamen, $\mathrm{LDCH}=$ left dorsal caudate nucleus, $\mathrm{RDCH}=$ right dorsal caudate nucleus.

Table 3 Relationship between Cortisol Levels and Amphetamine-Induced Dopamine Release ${ }^{a}$

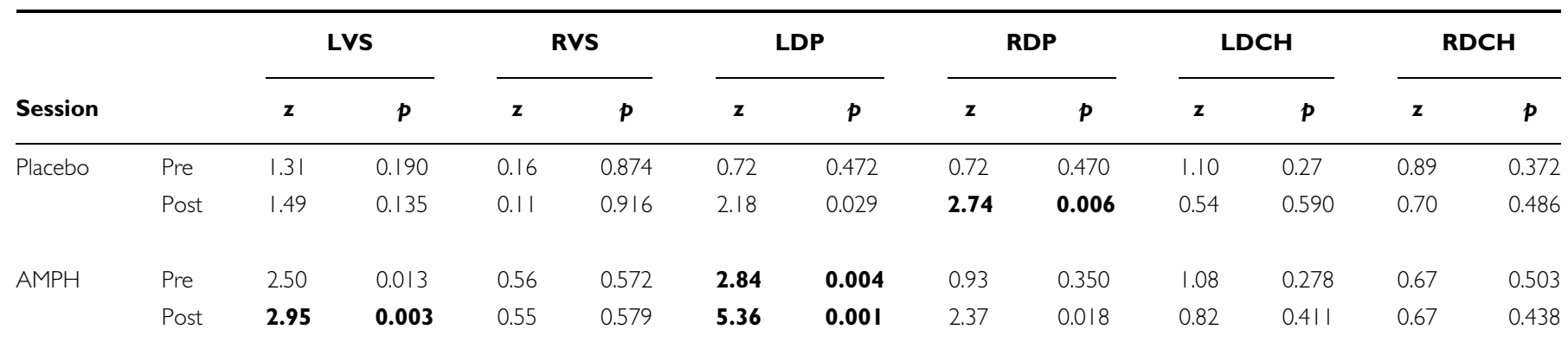

a Values significant at or below Bonferroni corrected level of 0.008 are in bold; analyses are adjusted for gender and drinking history. LVS = left ventral striatum, $\mathrm{RVS}=$ right ventral striatum, $\mathrm{LDP}=$ left dorsal putamen, $\mathrm{RDP}=$ right dorsal putamen, $\mathrm{LDCH}=$ left dorsal caudate nucleus, $\mathrm{RDCH}=$ right dorsal caudate nucleus, $\mathrm{AMPH}=$ amphetamine, Pre $=$ prior to drug administration, Post = following drug administration. 
$p=0.008$ ). In contrast to the findings for cortisol, no significant relationships were observed between GH response to AMPH and DA release in any of the defined regions of the striatum. However, significant negative associations were found between placebo session GH levels and DA release in all regions except the LVS and LDCH ( $p$-values $<0.008)$.

\section{Cortisol and Subjective Drug Effects}

No differences were observed in baseline analog ratings between sessions except for 'fidgety' ratings, which were higher before the AMPH session than before the placebo session $(t=-2.22, p=0.045)$. Drug effects were noted on analog measures of 'high', 'rush', 'good effects', 'liking', 'desire for drug'; ratings on each of these positive effect scales were higher during the AMPH session than during the placebo session $(p<0.05$ in all cases). Higher cortisol levels during the PET scans were associated with higher AMPH session self-report ratings of 'high' $\left(t_{11}=5.12\right.$, $p=0.0003)$, 'rush' $\left(t_{11}=5.70, p=0.0001\right)$, 'good effects' $\left(t_{11}=3.83, p=0.0028\right)$, 'like' $\left(t_{11}=4.41, p=0.0010\right)$, and 'desire for drug' $\left(t_{11}=4.30, p=0.0013\right)$. These relationships all met the Bonferroni adjusted criterion of $p<0.005$. Cortisol levels were not associated with ratings of negative drug effects during the AMPH session or with scores on any of the analog scales during the placebo session. Relation-

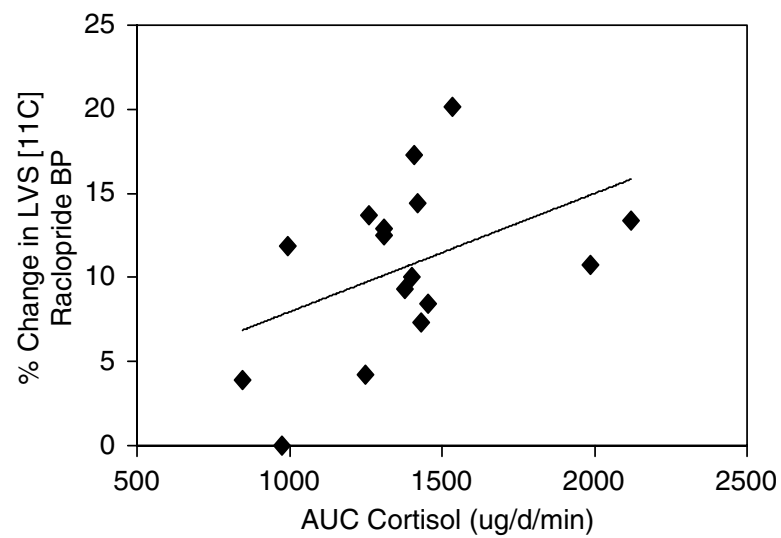

Figure 2 Unadjusted relationship between amphetamine-induced left ventral striatal (LVS) dopamine release and cortisol responses (AUC) to intravenous amphetamine. ships between cortisol AUC and two of the positive subjective responses to AMPH are shown in Figure 3. GH levels were not associated with any of the positive subjective effects of AMPH or with any subjective drug effects during the placebo scan, but were positively associated with AMPH session 'dry mouth' $\left(t_{11}=3.14, p=0.0013\right)$.

\section{DA Release and Subjective Drug Effects}

Findings showed some positive associations between the subjective effects of AMPH and DA release in each of the defined subregions of the striatum with the exception of the RVS (see Table 4). Relationships between LVS DA release and scores on two of the analog scales are shown in Figure 4. No associations were noted between ratings of
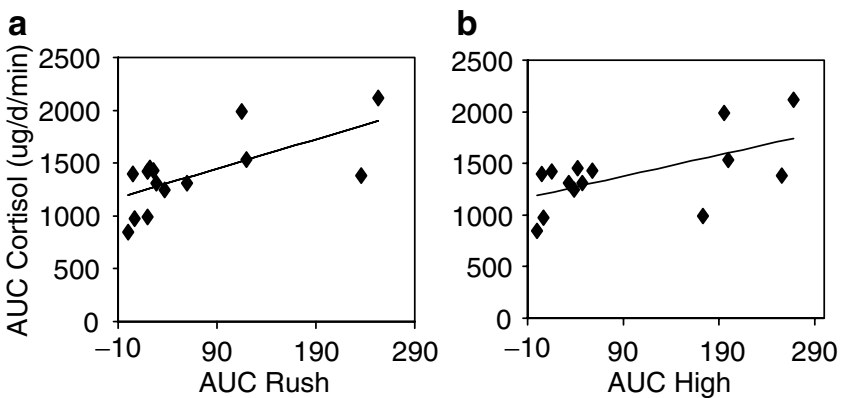

Figure 3 Unadjusted relationships between cortisol responses (AUC) to intravenous amphetamine and analog ratings (AUC) of rush (a) and high (b).
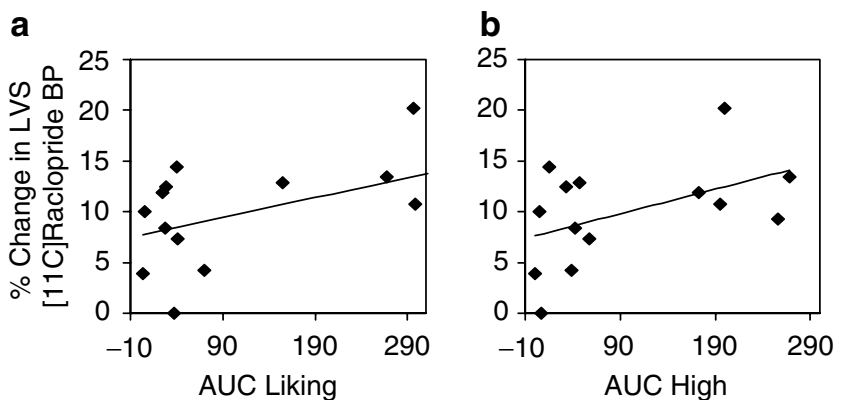

Figure 4 Unadjusted relationships between amphetamine-induced left ventral striatal (LVS) dopamine release and analog ratings (AUC) of liking (a) and high (b).

Table 4 Relationship between Positive Subjective Responses to Amphetamine and Dopamine Release ${ }^{a}$

\begin{tabular}{|c|c|c|c|c|c|c|c|c|c|c|c|c|}
\hline \multirow[b]{2}{*}{ Analog measure } & \multicolumn{2}{|c|}{ LVS } & \multicolumn{2}{|c|}{ RVS } & \multicolumn{2}{|c|}{ LDP } & \multicolumn{2}{|c|}{ RDP } & \multicolumn{2}{|c|}{ LDCH } & \multicolumn{2}{|c|}{ RDCH } \\
\hline & $\mathbf{z}$ & $p$ & $\mathbf{z}$ & $p$ & $\mathbf{z}$ & $p$ & $\mathbf{z}$ & $p$ & $\mathbf{z}$ & $p$ & $\mathbf{z}$ & $p$ \\
\hline $\mathrm{RUSH}$ & 3.18 & 0.001 & 1.17 & 0.242 & 2.68 & 0.007 & 2.81 & 0.005 & 2.21 & 0.027 & 2.44 & 0.015 \\
\hline GOOD & 3.02 & 0.003 & 0.78 & 0.435 & 1.99 & 0.047 & 2.58 & 0.010 & 1.32 & 0.187 & 1.57 & 0.116 \\
\hline
\end{tabular}

a Values significant at or below Bonferroni corrected level of 0.005 are in bold; analyses are adjusted for gender and drinking history. LVS $=$ left ventral striatum, $\mathrm{RVS}=$ right ventral striatum, $\mathrm{LDP}=$ left dorsal putamen, $\mathrm{RDP}=$ right dorsal putamen, $\mathrm{LDCH}=$ left dorsal caudate nucleus, $\mathrm{RDCH}=$ right dorsal caudate nucleus 
positive drug effects during the placebo session or negative drug effects during the AMPH session and AMPH-induced DA release. However, placebo session 'fidgety' ratings were negatively associated with DA release in all regions with the exception of the LVS and the RDCH ( $p<0.003$ in all cases).

\section{DISCUSSION}

This investigation was designed to examine relationships between cortisol levels, mesolimbic DA release, and subjective drug responses to AMPH in healthy human volunteers. Three important observations emerged from the data. First, higher cortisol levels were associated with greater AMPH-induced DA release in several regions of the striatum, including the LVS, LDP, and RDP. Second, subjects with higher cortisol levels reported more positive subjective effects with AMPH (ie 'high', 'rush', 'drug liking', 'good effects', and 'desire for drug') than subjects with lower cortisol levels. Third, higher ratings of positive subjective responses to AMPH were also associated with greater DA release in the several subregions of the striatum, including the LVS, LDP, RDP, LDCH, and RDCH. In contrast to the findings for cortisol, a general lack of relationship was observed between AMPH-induced GH and subjective drug responses or DA release, suggesting that the findings were specific to cortisol and cannot be generalized to all 'stress' hormones.

Findings from in vivo microdialysis studies indicate that a variety of laboratory stressors increase mesocorticolimbic DA activity in animals (Cadoni et al, 2003; Cuadra et al, 2001; Piazza and Le Moal, 1998; Tidey and Miczek, 1996). Stress has been reported to cross-sensitize to both psychostimulants (Kosten et al, 2003; Sorg, 1992) and alcohol (Yavich and Tiihonen, 2000), leading to greater increases in striatal DA concentrations following drug administration. Moreover, innate differences in reactivity to mild stressors are associated with differences in vulnerability to acquire amphetamine (AMPH) administration, as well as with differences in basal levels of DA in the $\mathrm{NA}_{\mathrm{cc}}$, and mesolimbic DA release in response to stress or drug challenges (Kosten and Ambrosio, 2002; Rouge-Pont et al, 1993). Chronic stress has also been noted to produce many of the same biochemical adaptations in the mesolimbic DA system as long-term drug administration (Ortiz et al, 1996).

Pruessner et al (2004) recently conducted a landmark PET study showing that ventral striatal $\left[{ }^{11} \mathrm{C}\right] \mathrm{RAC}$ binding was decreased (ie DA concentration increased) in response to a psychosocial stressor in humans who reported low early life maternal care. Importantly, the change in $\left[{ }^{11} \mathrm{C}\right] \mathrm{RAC}$ binding was positively associated with salivary cortisol responses to the stressor in the whole sample, providing the first evidence of a relationship between glucocorticoid levels and DA release in humans. Our data now extend these findings by showing that the relationship between glucocorticoids and DA is manifested in response to psychostimulant administration, as well as in response to a psychological challenge and can be detected by measuring either plasma or salivary cortisol levels. These parallels across studies suggest that psychological stressors and rewarding pharmacological agents may share the same physiological mechanisms in simultaneously elevating DA and cortisol levels.

Our findings are consistent with evidence from preclinical studies suggesting that glucocorticoids alter sensitivity to the reinforcing effects of alcohol and other drugs of abuse through their interactions with the mesolimbic DA system. Glucocorticoid receptors have been identified in the $\mathrm{NA}_{\mathrm{cc}}$ or VTA and there is evidence that high physiological levels of glucocorticoids facilitate DA release, modulate the functional activity of postsynaptic DA receptors, and increase synaptic strength in midbrain DA neurons (Barrot et al, 2000; Cho and Little, 1999; Deroche et al, 1995; Piazza et al, 1996; Saal et al, 2003). High levels of glucocorticoids increase rates of responding for psychostimulant drugs (Goeders and Guerin, 1996b; Piazza et al, 1991) and facilitate locomotor responses to psychostimulants injected into the $\mathrm{NA}_{\mathrm{cc}}$ in a DA-dependent manner (Marinelli and Piazza, 2002). Several methods of glucocorticoid suppression, such as synthesis blockade with ketoconazole, receptor antagonism with mifepristone, as well as adrenalectomy inhibit drug-seeking behavior in animal studies. Adrenalectomy has also been shown to reduce extracellular DA concentration in the $\mathrm{NA}_{\mathrm{cc}}$ shell in response to both psychostimulants and stress (Barrot et al, 2001).

Given these findings, it is surprising that data from most human studies have not been consistent with the preclinical literature in showing a relationship between glucocorticoids and psychostimulant reinforcement. Although findings from one human laboratory study indicated that intravenous cortisol administration increased reports of craving in cocaine abusers (Elman et al, 2003), the majority of findings in this area of research have been negative. For example, pharmacological blockade of drug-induced increases in cortisol did not alter the subjective responses to psychostimulants in humans in several studies (Harris et al, 2003; Ward et al, 1998, 1999), nor did it modify patterns of cocaine self-administration in non-human primates (Broadbear et al, 1999). Furthermore, treatment with cortisol synthesis inhibitors has been reported to increase cocaine use in methadone maintained patients with a history of cocaine abuse (Kosten et al, 2002). Negative findings have also been reported in studies examining the influence of hydrocortisone on physiological, behavioral, and/or subjective responses to AMPH in human volunteers (Hearn et al, 2004; Wachtel et al, 2001), as well as in one study that examined relationships between salivary cortisol levels and drug reinforcement following oral AMPH administration (Alessi et al, 2003).

How does one reconcile our findings showing strong relationships among cortisol secretion, AMPH-induced mesolimbic DA release, and positive subjective responses to AMPH with the prior human literature showing negative relationships between cortisol activity and subjective drug responses? Several methodological issues may account for the negative findings in the prior human literature. First, findings related to glucocorticoid synthesis inhibitors need to be interpreted cautiously since these agents not only alter glucocorticoid levels, but also modify the bioactivity of other steroids (Marinelli and Piazza, 2002) and dramatically increase secretion of corticotropin-releasing hormone (CRH) and adrenocorticotropic hormone (ACTH). Thus, the interpretation of findings from studies using these 
agents is not straightforward. Second, high or sustained levels of corticosterone are generally needed to modify drug self-administration behavior in rodents; these levels are achieved by administering stress-level doses of corticosterone or, more often, by repeated or prolonged stress exposure. It is possible that the changes produced by single or subchronic doses of hydrocortisone in humans are not comparable to those that facilitate drug self-administration in animals.

We propose a model in which frequent bouts of stress are associated with intermittent, but chronic exposure to high glucocorticoid levels that produces sensitization of the mesolimbic DA system. In this hypothetical model, sensitization could lead to amplification of DA release following psychostimulant administration and, consequently, increased drug reinforcement. Although our findings support the notion that individual differences in cortisol responsivity underlie differences in vulnerability for addiction, we do not believe that it is the acute druginduced rise in cortisol itself that mediates the subjective effects of the drug. In the present study, high cortisol producers in response to AMPH were also high cortisol producers in response to placebo. These individuals appear to be high stress responders who may have chronically elevated glucocorticoid levels as a function of either genetic and/or environmental factors. In this regard, the rise in cortisol during the scans may signal a mesolimbic system that has already been sensitized by repeated HPA axis activations. This interpretation is consistent with prior observations that stimulant-induced increases in glucocorticoids are not themselves critical to drug self-administration in animals (Marinelli and Piazza, 2002).

A limitation of the present study is that firm conclusions about the causal nature of the relationship between glucocorticoids and drug reinforcement cannot be established due to the correlational nature of the design, nor can we rule out the possibility that there may be another factor associated with stress that accounts for the changes in both glucocorticoid levels and subjective drug responses. There is considerable evidence that both extrahypothalamic and hypothalamic $\mathrm{CRH}$ mediate the actions of drugs of abuse (Sarnyai et al, 2001). Thus, activation of CRH pathways may be the primary mediator of stress-induced sensitization to drugs and glucocorticoids merely the surrogates of this relationship. Mendelson et al (2002) recently showed a temporal concordance between cocaine-induced stimulation of ACTH and subjective euphoria, suggesting that events mediating the relationship between HPA axis activity and drug reinforcement may occur at or above the level of the adrenal gland. Additional research is needed to further clarify these relationships.

Consistent with findings of several prior PET and SPECT studies (Drevets et al, 2001; Laruelle et al, 1995; Leyton et al, 2002; Martinez et al, 2003), our data indicate that differences in subjective effects of AMPH can be least partially accounted for by differences in AMPH-induced DA release in healthy volunteers. AMPH administration decreased $\left[{ }^{11} \mathrm{C}\right] \mathrm{RAC}$ binding in all of the defined subregions of the striatum. Nevertheless, inspection of Figure 4 suggests that the associations between DA release and positive subjective effects of AMPH may have been driven by the scores of a few outliers and may actually be the weakest findings of the study. The fact that this relationship has been observed in several other PET studies attests to its validity (Drevets et al, 2001; Laruelle et al, 1995; Leyton et al, 2002; Martinez et al, 2003; Schlaepfer et al, 1997; Volkow et al, 1999, 2002b). The apparently weaker findings in our study may reflect differences in definitions of the ROIs or may be the result of relatively modest DA release scores in the sample as a whole. Nevertheless, DA release and subjective response scores of all subjects were within normal limits and appear to reflect 'real' measures of individual differences in biological and subjective responses.

Multiple intercorrelations were found between DA release values across regions indicating that subjects who had higher release in one area had higher release in another. Therefore, it is not surprising that the findings showing relationships between DA release and positive subjective drug effects generalized across regions. Although findings from animal studies suggest that the $\mathrm{NA}_{\mathrm{cc}}$ is the structure that is most important in drug reinforcement, findings from human PET studies with $\left[{ }^{11} \mathrm{C}\right] \mathrm{RAC}$ and $\mathrm{AMPH}$ have been somewhat variable. Inconsistencies have been reported with respect to the relative amount of DA that is released across striatal subregions with AMPH, the presence or absence of correlations between regional DA release values, and the specific subregions in which DA release has been linked to positive subjective drug effects (Drevets et al, 2001; Leyton et al, 2002; Martinez et al, 2003). Differences in methods, differences in the delineation of striatal subregions, and limitations associated with resolution may account for some of these inconsistencies.

An unexpected finding was that both positive subjective drug effects and cortisol responses to AMPH were positively correlated with LVS, but not RVS DA release. Since separate analyses were conducted for each of the defined subregions of the striatum in the present investigation, caution is warranted in interpreting the meaning of these apparent differences across subregions. However, it should be noted that lateralization differences have been reported in glucose metabolism in the orbitofrontal cortex in humans following methylphenidate (Volkow et al, 2003), as well as in cerebral blood flow in the prefrontal (Tiihonen et al, 1994) and posterior (Wendt et al, 1994) cortex following alcohol. There is also evidence that specific binding of DA D2/D3 receptors is decreased in the left temporal brain (Kuikka et $a l, 2000)$ and that presynaptic DA function is diminished in the left caudate of type 1 alcoholics (Tiihonen et al, 1998).

One caveat of the present study is that the placebo scan was always conducted before the AMPH scan due to the potential carryover effects of AMPH. Although there is currently no evidence of diurnal variation in basal levels of endogenous DA, it is possible that other extraneous variables that may be associated with order, such as anticipatory anxiety, could have an influence on endogenous DA levels and response to AMPH. Baseline anxiety was positively associated with DA release following methylphenidate in one study (Volkow et al, 1994) and change in anxiety following AMPH was negatively correlated with DA release in another (Drevets et al, 2001). No differences in baseline anxiety were noted on the analog scales between sessions and analog ratings of anxiety were not associated with DA release in the present study. Future studies with 
larger sample sizes will allow further investigation of these and other covariates. An alternative to the present design would have been to counterbalance the order of the two drug conditions by administering them on different days. With the latter alternative, however, the design would have been compromised by less experimental control over confounding variables between sessions, as well as greater likelihood that some subjects might not complete both scans. A possible advantage of the fixed order of the scans was that the AMPH scan was always conducted as the second scan of the day during the mid-morning hours when cortisol levels would normally be falling, giving added credence to conclusions that the increases in hormone levels that were observed during this period of time were druginduced effects.

In summary, our findings provide support for notions that glucocorticoids play a role in psychostimulant reinforcement and that interactions between glucocorticoids and DA neurotransmission underlie this role. The findings have implications for the development of new pharmacotherapies for alcohol and drug dependence, suggesting that efforts to develop therapeutic agents that target the HPA axis hold promise for the future. The data also support hypotheses that individual differences in stress reactivity may be a factor that influences vulnerability for alcohol and drug dependence.

\section{ACKNOWLEDGEMENTS}

This work was supported by NIH Grants RO1 AA10158 (GSW), RO1 AA12837 (MEM), RO1 AA12839 (DFW), K24 DA00412 (DFW), F32 AA013681 (LMO), M01 RR00052 (GCRC) and a generous gift from The Kenneth Lattman Foundation (GSW).

\section{REFERENCES}

Alessi SM, Greenwald M, Johanson CE (2003). The prediction of individual differences in response to D-amphetamine in healthy adults. Behav Pharmacol 14: 19-32.

Backman L, Ginovart N, Dixon RA, Wahlin TB, Wahlin A, Halldin $C$ et al (2000). Age-related cognitive deficits mediated by changes in the striatal dopamine system. Am J Psychiatry 157: 635-637.

Barrot M, Abrous DN, Marinelli M, Rouge-Pont F, Le Moal M, Piazza PV (2001). Influence of glucocorticoids on dopaminergic transmission in the rat dorsolateral striatum. Eur J Neurosci 13: 812-818.

Barrot M, Marinelli M, Abrous DN, Rouge-Pont F, Le Moal M, Piazza PV (2000). The dopaminergic hyper-responsiveness of the shell of the nucleus accumbens is hormone-dependent. Eur J Neurosci 12: 973-979.

Bau CH, Almeida S, Hutz MH (2000). The TaqI A1 allele of the dopamine $\mathrm{D} 2$ receptor gene and alcoholism in Brazil: association and interaction with stress and harm avoidance on severity prediction. Am J Med Genet 96: 302-306.

Baumann B, Danos P, Krell D, Diekmann S, Leschinger A, Stauch R et al (1999). Reduced volume of limbic system-affiliated basal ganglia in mood disorders: preliminary data from a postmortem study. J Neuropsychiatry Clin Neurosci 11: 71-78.

Bigelow G, Walsh S (1998). Evaluation of potential pharmacotherapies: response to cocaine challenge in the human laboratory. In: Higgins S, Katz J (eds). Cocaine Abuse: Behavior, Pharmacology and Clinical Applications. Academic Press: New York. pp 209-238.
Bonci A, Bernardi G, Grillner P, Mercuri NB (2003). The dopamine-containing neuron: maestro or simple musician in the orchestra of addiction? Trends Pharmacol Sci 24: 172-177.

Brewer DD, Catalano RF, Haggerty K, Gainey RR, Fleming CB (1998). A meta-analysis of predictors of continued drug use during and after treatment for opiate addiction. Addiction 93: 73-92.

Broadbear JH, Winger G, Woods JH (1999). Cocaine-reinforced responding in rhesus monkeys: pharmacological attenuation of the hypothalamic-pituitary-adrenal axis response. J Pharmacol Exp Ther 290: 1347-1355.

Brown SA, Vik PW, McQuaid JR, Patterson TL, Irwin MR, Grant I (1990). Severity of psychosocial stress and outcome of alcoholism treatment. J Abnorm Psychol 99: 344-348.

Bucholz KK, Cadoret R, Cloninger CR, Dinwiddie SH, Hesselbrock VM, Nurnberger Jr JI et al (1994). A new, semi-structured psychiatric interview for use in genetic linkage studies: a report on the reliability of the SSAGA. J Stud Alcohol 55: 149-158.

Cadoni C, Solinas M, Valentini V, Di Chiara G (2003). Selective psychostimulant sensitization by food restriction: differential changes in accumbens shell and core dopamine. Eur J Neurosci 18: 2326-2334.

Campbell UC, Carroll ME (2001). Effects of ketoconazole on the acquisition of intravenous cocaine self-administration under different feeding conditions in rats. Psychopharmacology (Berl) 154: 311-318.

Cho K, Little HJ (1999). Effects of corticosterone on excitatory amino acid responses in dopamine-sensitive neurons in the ventral tegmental area. Neuroscience 88: 837-845.

Cole G, Tucker L, Friedman GM (1990). Relationships among measures of alcohol drinking behavior, life-events and perceived stress. Psychol Rep 67: 587-591.

Collignon A, Maes F, Delaere D, Vandermeulen D, Suetens P, Marchal G (1995). Automated multi-modality image registration based on information theory. In: Bizais Y, Barillot C, Di Paola R (eds). Proceedings Information Processing in Medical Imaging. Kluwer Academic Publishers: Dordrecht, The Netherlands. pp 263-274.

Cuadra G, Zurita A, Gioino G, Molina V (2001). Influence of different antidepressant drugs on the effect of chronic variable stress on restraint-induced dopamine release in frontal cortex. Neuropsychopharmacology 25: 384-394.

Dai X, Thavundayil J, Gianoulakis C (2002a). Differences in the responses of the pituitary beta-endorphin and cardiovascular system to ethanol and stress as a function of family history. Alcohol Clin Exp Res 26: 1171-1180.

Dai X, Thavundayil J, Gianoulakis C (2002b). Response of the hypothalamic-pituitary-adrenal axis to stress in the absence and presence of ethanol in subjects at high and low risk of alcoholism. Neuropsychopharmacology 27: 442-452.

Deroche V, Marinelli M, Maccari S, Le Moal M, Simon H, Piazza PV (1995). Stress-induced sensitization and glucocorticoids. I. Sensitization of dopamine-dependent locomotor effects of amphetamine and morphine depends on stress-induced corticosterone secretion. J Neurosci 15: 7181-7188.

Deroche V, Marinelli M, Le Moal M, Piazza PV (1997). Glucocorticoids and behavioral effects of psychostimulants. II: cocaine intravenous self-administration and reinstatement depend on glucocorticoid levels. J Pharmacol Exp Ther 281: 1401-1407.

de Wit H, Soderpalm AH, Nikolayev L, Young E (2003). Effects of acute social stress on alcohol consumption in healthy subjects. Alcohol Clin Exp Res 27: 1270-1277.

Doyon WM, York JL, Diaz LM, Samson HH, Czachowski CL, Gonzales RA (2003). Dopamine activity in the nucleus accumbens during consummatory phases of oral ethanol self-administration. Alcohol Clin Exp Res 27: 1573-1582. 
Drevets WC, Gautier C, Price JC, Kupfer DJ, Kinahan PE, Grace AA et al (2001). Amphetamine-induced dopamine release in human ventral striatum correlates with euphoria. Biol Psychiatry 49: 81-96.

Elman I, Lukas SE, Karlsgodt KH, Gasic GP, Breiter HC (2003). Acute cortisol administration triggers craving in individuals with cocaine dependence. Psychopharmacol Bull 37: 84-89.

Endres CJ, Kolachana BS, Saunders RC, Su T, Weinberger D, Breier A et al (1997). Kinetic modeling of [11C]raclopride: combined PET-microdialysis studies. J Cereb Blood Flow Metab 17: 932-942.

Erb S, Shaham Y, Stewart J (1996). Stress reinstates cocaineseeking behavior after prolonged extinction and a drug-free period. Psychopharmacology (Berl) 128: 408-412.

Errico AL, King AC, Lovallo WR, Parsons OA (2002). Cortisol dysregulation and cognitive impairment in abstinent male alcoholics. Alcohol Clin Exp Res 26: 1198-1204.

Fahlke C, Engel JA, Eriksson CJ, Hard E, Soderpalm B (1994). Involvement of corticosterone in the modulation of ethanol consumption in the rat. Alcohol 11: 195-202.

Friston KJ. http://www.fil.ion.ucl.ac.uk/spm.2002. electronic citation.

Goeders NE, Clampitt DM (2002). Potential role for the hypothalamo-pituitary-adrenal axis in the conditioned reinforcer-induced reinstatement of extinguished cocaine seeking in rats. Psychopharmacology (Berl) 161: 222-232.

Goeders NE, Guerin GF (1996a). Effects of surgical and pharmacological adrenalectomy on the initiation and maintenance of intravenous cocaine self-administration in rats. Brain Res 722: $145-152$.

Goeders NE, Guerin GF (1996b). Role of corticosterone in intravenous cocaine self-administration in rats. Neuroendocrinology 64: 337-348.

Halbreich U, Sachar EJ, Asnis GM, Nathan RS, Halpern FS (1981). Diurnal cortisol responses to dextroamphetamine in normal subjects. Psychoneuroendocrinology 6: 223-229.

Harris DS, Reus VI, Wolkowitz OM, Mendelson JE, Jones RT (2003). Altering cortisol level does not change the pleasurable effects of methamphetamine in humans. Neuropsychopharmacology 28: 1677-1684.

Hearn AJ, Gallagher P, Owen BM, Smith MS, Watson S, Young AH (2004). Effect of sub-chronic hydrocortisone on responses to amphetamine in normal male volunteers. Psychopharmacology (Berl) 171: 458-464.

Howell LL, Wilcox KM (2002). Functional imaging and neurochemical correlates of stimulant self-administration in primates. Psychopharmacology (Berl) 163: 352-361.

Hull JG, Young RD (1983). Self-consciousness, self-esteem, and success-failure as determinants of alcohol consumption in male social drinkers. J Pers Soc Psychol 44: 1097-1109.

Jacobs D, Silverstone T, Rees L (1989). The neuroendocrine response to oral dextroamphetamine in normal subjects. Int Clin Psychopharmacol 4: 135-147.

Karlsgodt KH, Lukas SE, Elman I (2003). Psychosocial stress and the duration of cocaine use in non-treatment seeking individuals with cocaine dependence. Am J Drug Alcohol Abuse 29: 539-551.

Kemper A, Koalick F, Thiele H, Retzow A, Rathsack R, Nickel B (1990). Cortisol and beta-endorphin response in alcoholics and alcohol abusers following a high naloxone dosage. Drug Alcohol Depend 25: 319-326.

King AC, Bernardy NC, Hauner K (2003). Stressful events, personality, and mood disturbance: gender differences in alcoholics and problem drinkers. Addict Behav 28: 171-187.

King AC, Schluger J, Gunduz M, Borg L, Perret G, Ho A et al (2002). Hypothalamic-pituitary-adrenocortical (HPA) axis response and biotransformation of oral naltrexone: preliminary examination of relationship to family history of alcoholism. Neuropsychopharmacology 26: 778-788.
Koenig HN, Olive MF (2004). The glucocorticoid receptor antagonist mifepristone reduces ethanol intake in rats under limited access conditions. Psychoneuroendocrinology 29: 999-1003.

Koob GF (1992). Drugs of abuse: anatomy, pharmacology and function of reward pathways. Trends Pharmacol Sci 13: 177-184.

Koob GF (2003). Alcoholism: allostasis and beyond. Alcohol Clin Exp Res 27: 232-243.

Kosten TA, Ambrosio E (2002). HPA axis function and drug addictive behaviors: insights from studies with Lewis and Fischer 344 inbred rats. Psychoneuroendocrinology 27: 35-69.

Kosten TA, Zhang XY, Kehoe P (2003). Chronic neonatal isolation stress enhances cocaine-induced increases in ventral striatal dopamine levels in rat pups. Brain Res Dev Brain Res 141: 109-116.

Kosten TR, Oliveto A, Sevarino KA, Gonsai K, Feingold A (2002). Ketoconazole increases cocaine and opioid use in methadone maintained patients. Drug Alcohol Depend 66: 173-180.

Kreek MJ, Koob GF (1998). Drug dependence: stress and dysregulation of brain reward pathways. Drug Alcohol Depend 51: 23-47.

Kuikka JT, Repo E, Bergstrom KA, Tupala E, Tiihonen J (2000). Specific binding and laterality of human extrastriatal dopamine D2/D3 receptors in late onset type 1 alcoholic patients. Neurosci Lett 292: 57-59.

Lammertsma AA, Hume SP (1996). Simplified reference tissue model for PET receptor studies. Neuroimage 4: 153-158.

Laruelle M, Abi-Dargham A, van Dyck CH, Rosenblatt W, ZeaPonce Y, Zoghbi SS et al (1995). SPECT imaging of striatal dopamine release after amphetamine challenge. J Nucl Med 36: $1182-1190$.

Le AD, Quan B, Juzytch W, Fletcher PJ, Joharchi N, Shaham Y (1998). Reinstatement of alcohol-seeking by priming injections of alcohol and exposure to stress in rats. Psychopharmacology (Berl) 135: 169-174.

Leyton M, Boileau I, Benkelfat C, Diksic M, Baker G, Dagher A (2002). Amphetamine-induced increases in extracellular dopamine, drug wanting, and novelty seeking: a PET/[11C] raclopride study in healthy men. Neuropsychopharmacology 27: 1027-1035.

Liu X, Weiss F (2002). Reversal of ethanol-seeking behavior by D1 and D2 antagonists in an animal model of relapse: differences in antagonist potency in previously ethanol-dependent versus nondependent rats. J Pharmacol Exp Ther 300: 882-889.

Madrid GA, MacMurray J, Lee JW, Anderson BA, Comings DE (2001). Stress as a mediating factor in the association between the DRD2 TaqI polymorphism and alcoholism. Alcohol 23: 117-122.

Marinelli M, Piazza PV (2002). Interaction between glucocorticoid hormones, stress and psychostimulant drugs. Eur J Neurosci 16: 387-394.

Martinez D, Slifstein M, Broft A, Mawlawi O, Hwang DR, Huang Y et al (2003). Imaging human mesolimbic dopamine transmission with positron emission tomography. Part II: amphetamineinduced dopamine release in the functional subdivisions of the striatum. J Cereb Blood Flow Metab 23: 285-300.

Mendelson JH, Mello NK, Sholar MB, Siegel AJ, Mutschler N, Halpern J (2002). Temporal concordance of cocaine effects on mood states and neuroendocrine hormones. Psychoneuroendocrinology 27: 71-82.

Ohannessian CM, Hesselbrock VM, Tennen H, Affleck G (1994). Hassles and uplifts and generalized outcome expectancies as moderators on the relation between a family history of alcoholism and drinking behaviors. J Stud Alcohol 55: 754-763.

Ortiz J, Fitzgerald LW, Lane S, Terwilliger R, Nestler EJ (1996). Biochemical adaptations in the mesolimbic dopamine system in response to repeated stress. Neuropsychopharmacology 14: 443-452. 
Phillips TJ, Brown KJ, Burkhart-Kasch S, Wenger CD, Kelly MA, Rubinstein $\mathrm{M}$ et al (1998). Alcohol preference and sensitivity are markedly reduced in mice lacking dopamine D2 receptors. Nat Neurosci 1: 610-615.

Piazza PV, Le Moal M (1997). Glucocorticoids as a biological substrate of reward: physiological and pathophysiological implications. Brain Res Brain Res Rev 25: 359-372.

Piazza PV, Le Moal M (1998). The role of stress in drug selfadministration. Trends Pharmacol Sci 19: 67-74.

Piazza PV, Maccari S, Deminiere JM, Le Moal M, Mormede P, Simon H (1991). Corticosterone levels determine individual vulnerability to amphetamine self-administration. Proc Natl Acad Sci USA 88: 2088-2092.

Piazza PV, Rouge-Pont F, Deroche V, Maccari S, Simon H, Le Moal M (1996). Glucocorticoids have state-dependent stimulant effects on the mesencephalic dopaminergic transmission. Proc Natl Acad Sci USA 93: 8716-8720.

Pruessner JC, Champagne F, Meaney MJ, Dagher A (2004). Dopamine release in response to a psychological stress in humans and its relationship to early life maternal care: a positron emission tomography study using [11C]raclopride. J Neurosci 24: 2825-2831.

Rouge-Pont F, Piazza PV, Kharouby M, Le Moal M, Simon H (1993). Higher and longer stress-induced increase in dopamine concentrations in the nucleus accumbens of animals predisposed to amphetamine self-administration. A microdialysis study. Brain Res 602: 169-174.

Saal D, Dong Y, Bonci A, Malenka RC (2003). Drugs of abuse and stress trigger a common synaptic adaptation in dopamine neurons. Neuron 37: 577-582.

Samson HH, Hodge CW (1993). The role of the mesoaccumbens dopamine system in ethanol reinforcement: studies using the techniques of microinjection and voltammetry. Alcohol Alcohol Suppl 2: 469-474.

Sarnyai Z, Shaham Y, Heinrichs SC (2001). The role of corticotropin-releasing factor in drug addiction. Pharmacol Rev 53: 209-243.

Schad CA, Justice Jr JB, Holtzman SG (2002). Endogenous opioids in dopaminergic cell body regions modulate amphetamine-induced increases in extracellular dopamine levels in the terminal regions. J Pharmacol Exp Ther 300: 932-938.

Schlaepfer TE, Pearlson GD, Wong DF, Marenco S, Dannals RF (1997). PET study of competition between intravenous cocaine and $[11 \mathrm{C}]$ raclopride at dopamine receptors in human subjects. Am J Psychiatry 154: 1209-1213.

Schmitz Y, Lee CJ, Schmauss C, Gonon F, Sulzer D (2001). Amphetamine distorts stimulation-dependent dopamine overflow: effects on D2 autoreceptors, transporters, and synaptic vesicle stores. J Neurosci 21: 5916-5924.

Schuckit MA, Tsuang JW, Anthenelli RM, Tipp JE, Nurnberger Jr JI (1996). Alcohol challenges in young men from alcoholic pedigrees and control families: a report from the COGA project. I Stud Alcohol 57: 368-377.

Shaham Y, Erb S, Stewart J (2000). Stress-induced relapse to heroin and cocaine seeking in rats: a review. Brain Res Brain Res Rev 33: 13-33.

Sinha R, Catapano D, O’Malley S (1999). Stress-induced craving and stress response in cocaine dependent individuals. Psychopharmacology (Berl) 142: 343-351.

Sinha R, Fuse T, Aubin LR, O'Malley SS (2000). Psychological stress, drug-related cues and cocaine craving. Psychopharmacology (Berl) 152: 140-148.

Sinha R, Talih M, Malison R, Cooney N, Anderson GM, Kreek MJ (2003). Hypothalamic-pituitary-adrenal axis and sympathoadreno-medullary responses during stress-induced and drug cue-induced cocaine craving states. Psychopharmacology (Berl) 170: 62-72.
Smith SM, Vaughan JM, Donaldson CJ, Rivier J, Li C, Chen A et al (2004). Cocaine- and amphetamine-regulated transcript activates the hypothalamic-pituitary-adrenal axis through a corticotropin-releasing factor receptor-dependent mechanism. Endocrinology 145: 5202-5209.

Soderpalm AH, de Wit H (2002). Effects of stress and alcohol on subjective state in humans. Alcohol Clin Exp Res 26: 818-826.

Sorg BA (1992). Mesocorticolimbic dopamine systems: crosssensitization between stress and cocaine. Ann NY Acad Sci 654: 136-144.

Spanagel R, Weiss F (1999). The dopamine hypothesis of reward: past and current status. Trends Neurosci 22: 521-527.

Sussman S, Dent CW (2000). One-year prospective prediction of drug use from stress-related variables. Subst Use Misuse 35: 717-735.

Swerdlow NR, Koob GF, Cador M, Lorang M, Hauger RL (1993). Pituitary-adrenal axis responses to acute amphetamine in the rat. Pharmacol Biochem Behav 45: 629-637.

Tidey JW, Miczek KA (1996). Social defeat stress selectively alters mesocorticolimbic dopamine release: an in vivo microdialysis study. Brain Res 721: 140-149.

Tiihonen J, Kuikka J, Hakola P, Paanila J, Airaksinen J, Eronen M et al (1994). Acute ethanol-induced changes in cerebral blood flow. Am J Psychiatry 151: 1505-1508.

Tiihonen J, Vilkman H, Rasanen P, Ryynanen OP, Hakko H, Bergman J et al (1998). Striatal presynaptic dopamine function in type 1 alcoholics measured with positron emission tomography. Mol Psychiatry 3: 156-161.

van Dyck CH, Seibyl JP, Malison RT, Laruelle M, Zoghbi SS, Baldwin RM et al (2002). Age-related decline in dopamine transporters: analysis of striatal subregions, nonlinear effects, and hemispheric asymmetries. Am J Geriatr Psychiatry 10: 36-43.

Volkow ND, Wang GJ, Fowler JS, Logan J, Franceschi D, Maynard L et al (2002a). Relationship between blockade of dopamine transporters by oral methylphenidate and the increases in extracellular dopamine: therapeutic implications. Synapse 43: 181-187.

Volkow ND, Wang GJ, Fowler JS, Logan J, Gatley SJ, Wong C et al (1999). Reinforcing effects of psychostimulants in humans are associated with increases in brain dopamine and occupancy of D(2) receptors. J Pharmacol Exp Ther 291: 409-415.

Volkow ND, Wang GJ, Fowler JS, Logan J, Schlyer D, Hitzemann R et al (1994). Imaging endogenous dopamine competition with [C-11] Raclopride in the human brain. Synapse 16: 255-262.

Volkow ND, Wang GJ, Fowler JS, Thanos PP, Logan J, Gatley SJ et al (2002b). Brain DA D2 receptors predict reinforcing effects of stimulants in humans: replication study. Synapse 46: 79-82.

Volkow ND, Wang GJ, Ma Y, Fowler JS, Zhu W, Maynard L et al (2003). Expectation enhances the regional brain metabolic and the reinforcing effects of stimulants in cocaine abusers. J Neurosci 23: 11461-11468.

Wachtel SR, Charnot A, de Wit H (2001). Acute hydrocortisone administration does not affect subjective responses to d-amphetamine in humans. Psychopharmacology (Berl) 153: 380-388.

Waltman C, McCaul ME, Wand GS (1994). Adrenocorticotropin responses following administration of ethanol and ovine corticotropin-releasing hormone in the sons of alcoholics and control subjects. Alcohol Clin Exp Res 18: 826-830.

Wang GJ, Volkow ND, Franceschi D, Fowler JS, Thanos PK, Scherbaum $\mathrm{N}$ et al (2000). Regional brain metabolism during alcohol intoxication. Alcohol Clin Exp Res 24: 822-829.

Wand G, McCaul ME, Gotjen D, Reynolds J, Lee S (2001). Confirmation that offspring from families with alcohol-dependent individuals have greater hypothalamic-pituitary-adrenal axis activation induced by naloxone compared with offspring 
Dopamine, cortisol, and subjective effects of amphetamine LM Oswald et al

without a family history of alcohol dependence. Alcohol Clin Exp Res 25: 1134-1139.

Wand GS, Mangold D, Ali M (1999a). Adrenocorticotropin responses to naloxone in sons of alcohol-dependent men. J Clin Endocrinol Metab 84: 64-68.

Wand GS, Mangold D, Ali M, Giggey P (1999b). Adrenocortical responses and family history of alcoholism. Alcohol Clin Exp Res 23: $1185-1190$.

Wand GS, Mangold D, El Deiry S, McCaul ME, Hoover D (1998). Family history of alcoholism and hypothalamic opioidergic activity. Arch Gen Psychiatry 55: 1114-1119.

Ward AS, Collins ED, Haney M, Foltin RW, Fischman MW (1998). Ketoconazole attenuates the cortisol response but not the subjective effects of smoked cocaine in humans. Behav Pharmacol 9: 577-586.

Ward AS, Collins ED, Haney M, Foltin RW, Fischman MW (1999). Blockade of cocaine-induced increases in adrenocorticotrophic hormone and cortisol does not attenuate the subjective effects of smoked cocaine in humans. Behav Pharmacol 10: 523-529.

Wendt PE, Risberg J, Stenberg G, Rosen I, Ingvar DH (1994). Ethanol reduces asymmetry of visual Rcbf responses. J Cereb Blood Flow Metab 14: 963-973.

Wise RA (1998). Drug-activation of brain reward pathways. Drug Alcohol Depend 51: 13-22.

Wong DF (2002). In vivo imaging of D2 dopamine receptors in schizophrenia: the ups and downs of neuroimaging research. Arch Gen Psychiatry 59: 31-34.

Yavich L, Tiihonen J (2000). Ethanol modulates evoked dopamine release in mouse nucleus accumbens: dependence on social stress and dose. Eur J Pharmacol 401: 365-373.

Zhou Y, Endres CJ, Brasic JR, Huang SC, Wong DF (2003). Linear regression with spatial constraint to generate parametric images of ligand-receptor dynamic PET studies with a simplified reference tissue model. Neuroimage 18: 975-989. 